\title{
Moral injury and well-being in essential workers during the COVID-19 pandemic: local survey findings
}

\author{
Catherine Guy (1) , ${ }^{1,2}$ Edward Kunonga, ${ }^{3}$ Angela Kennedy, ${ }^{4}$ Paras Patel ${ }^{3}$
}

\begin{abstract}
- Additional supplemental material is published online only. To view, please visit the journal online (http://dx.doi. org/10.1136/leader-2021000518).
\end{abstract}

${ }^{1}$ Medical Directorate, West Park Hospital, Tees Esk and Wear Valleys NHS Trust, Darlington, UK

${ }^{2}$ Public Health England, Newcastle, UK

${ }^{3}$ Tees Esk and Wear Valleys NHS Foundation Trust, Darlington, UK ${ }^{4}$ Cumbria Northumberland Tyne and Wear NHS Foundation Trust, Newcastle upon Tyne, UK

\section{Correspondence to}

Dr Catherine Guy, Medical

Directorate, West Park Hospital Tees Esk and Wear Valleys NHS Trust, Darlington DL2 2TS, UK ; catherineguy2@nhs.net

Received 24 May 2021

Accepted 15 December 2021

\section{ABSTRACT \\ Background Essential workers have faced many difficult situations working during the pandemic. Staff may feel that they, or other people, have acted wrongly and be distressed by this. This represents moral injury, which has been linked with significant mental ill health.}

Methods This survey asked essential workers in County Durham and Darlington about their experiences during the first wave of the pandemic and anything they felt would help. Well-being and moral injury were rated using sliders. Results There were 566 responses. A majority of respondents reported feeling troubled by other people's actions they felt were wrong ( $60 \%$ scored over 40 , where 0 is 'not at all troubled' and 100 'very troubled', median score $=52.5$. . Respondents were generally less troubled by their own actions (median score $=3$ ). Well-being and moral injury scores varied by employment sector (eg, National Health Service (NHS) staff were more troubled by the actions of others than non-NHS staff).

Staff suggestions included regular supervisor check-ins, ensuring kindness from everyone, fair rules and enforcement and improving communication and processes. Respondents offered simple, practical actions that could be taken by leaders at team, organisation, societal and governmental levels to tackle moral injury and the underlying causes of moral injurious environments.

Conclusion Using these findings to develop a strategy to address moral injury is important, not only for staff wellbeing, but staff retention and continued delivery of vital services in these challenging times. Working together, we can seek to reduce and mitigate 'moral injury' the same way we do for other physical workplace 'injuries'.

\section{BACKGROUND}

The COVID-19 pandemic has devastated many countries and communities across the world. Many governments took actions to prevent onwards transmission and ensure health systems were not overwhelmed.

Essential workers have faced not only the direct impact of the pandemic, and potential increased personal risk, but also moral dilemmas when guidance on ways of working contradicted standard practice. This includes staff in health and care, local government, education/childcare, food production/ sale and other key services who may feel unprepared for such dilemmas. Staff may believe that they, or other people, have acted wrongly during the pandemic and be distressed by this. This has been referred to in the literature as moral injury.

Greenberg et al describe moral injury as distress that results from actions (or inaction) which violate a person's moral/ethical code. ${ }^{1}$ These actions may have been committed by the person who is distressed or by someone else. A person who is morally injured may have negative thoughts about themselves or others (eg, 'I am a terrible person' or 'They don't care about people's lives') as well as intense feelings of shame, guilt or disgust. ${ }^{1}$ Examples of moral injury include distress at following/ giving instructions resulting in harm or feeling let down by insufficient resources. ${ }^{1}$ Moral injury is not a mental illness but it has been linked with anxiety, depression and suicide. ${ }^{2}$

Moral injury has been reported in a quarter of healthcare workers in some settings, ${ }^{3}$ though moral injury among essential workers in the UK, particularly during the COVID-19 pandemic, has not been described fully. Exploring these staff experiences means interventions could be tailored to need and are more likely to be successful. ${ }^{4}$

This survey sought to explore essential workers' experience of moral injury, actions staff felt were wrong and what might help with the ultimate aim of implementing effective action throughout the system. Whole system action, as opposed to individual-focussed approaches, is important since moral injurious environments are created through an interaction of government policy, organisational approaches, team dynamics and broader societal and social pressures.'

'Moral injury' is a helpful term, implying a need to address the cause of the injury rather than solely focusing on resolving individual distress. To prevent physical workplace injuries, employers are encouraged to learn from minor injuries not just severe injury. Therefore, this exploratory survey investigated the full continuum of moral injury and actions people feel are wrong.

\section{METHODS}

A local multiagency project group was established to address moral injury in essential workers. Members included Tees, Esk and Wear Valley NHS Foundation Trust, County Durham and Darlington NHS Foundation Trust, Durham County Council and Public Health England.

As part of a Needs Assessment and Service Evaluation, the group developed a survey to understand moral injury among essential workers working in County Durham and Darlington. The survey covered people defined by government as 'critical to the COVID-19 response'. ${ }^{6}$

The survey involved self-administered questions regarding actions staff felt were wrong and suggestions to prevent similar situations or reduce the impact. Respondents used sliders to rate their wellbeing and degree of moral injury they experienced.

The survey $\operatorname{link}^{7}$ was disseminated via members of the multiagency group and responses collected 
after the initial wave of COVID-19, between 24 September 2020 and 12 October 2020.

\section{Quantitative analysis}

Median scores for self-rated moral injury and well-being were calculated. Scores in particular employment sectors were compared with scores outside that sector using the MannWhitney test. Associations between moral injury scores and wellbeing were explored using the Pearson correlation coefficient.

\section{Qualitative analysis}

Thematic analysis of free-text comments regarding actions staff felt were wrong, and their suggestions, was conducted regardless of moral injury score since less distressed respondents may still have valid suggestions for preventing or mitigating future situations. Initial codes were compared with independent coding of a section of comments by a second researcher (PP). Codes were combined into themes which were repeatedly reviewed and amended to ensure that they covered comments provided, were clear in meaning and allowed for effective action.

\section{RESULTS}

There were 566 respondents $(79 \%$ female, median age group 45-49 years). Respondent employment sectors included NHS/ health (54\%), social care (17\%), local/national government $(15 \%)$, education/childcare $(9 \%)$ and others (5\%). Detailed demographics, scores by employment sector and correlation data are included in online supplemental tables. The most skipped scoring question related to how troubled respondents were by their own actions (16 respondents, $2.8 \%$ ).

\section{Moral injury and well-being scores}

Figure 1 shows a majority of respondents reported feeling troubled by other people's actions they felt were wrong (60\% scored over 40, where 0 is 'not at all troubled' and 100 'very troubled' and the median score was 52.5). Respondents were generally less troubled by their own actions (median score 3 ).

Respondents troubled by their own actions also tended to be troubled by other people's actions $(r=0.4091, p<0.0001)$ with all respondents scoring over 60 for the former, scoring 50 or more for the latter.

Both moral injury scores (troubled by own actions or others' actions) showed statistically significant negative correlations with physical well-being $(p=0.0008, p<0.0001)$, mental well-being
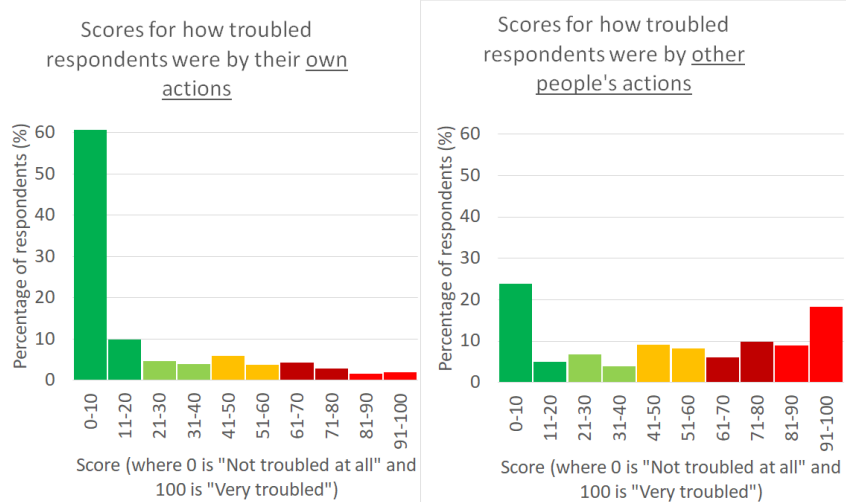

Figure 1 Comparison of how troubled respondents were by their own and other people's actions. $(\mathrm{p}<0.0001, \mathrm{p}<0.0001)$ and connectedness with colleagues $(\mathrm{p}=0.0275, \mathrm{p}=0.0165)$.

Overall, median scores for physical and emotional/mental well-being were 70 and 52.5, respectively (where 0 is 'very poor' and 100 'excellent'). Median scores for connectedness with colleagues and connectedness with others outside of work were 54 and 48 (where 0 is 'not close/very isolated' and 100 'very close/connected').

\section{Variation by employment sector}

Across employment sectors, there were statistically significant differences in moral injury and well-being:

- NHS/health staff reported being more troubled by the actions of others (median score 58, $\mathrm{p}=0.0334$ ) and lower mental well-being (median score $50, \mathrm{p}=0.0004$ ) than nonNHS staff.

- Social care sector staff reported feeling more connected to colleagues (median score 70) than non-social care staff $(\mathrm{p}=0.0010)$.

- Local/national government staff reported higher mental well-being (median score 63) than non-government staff $(\mathrm{p}=0.0472)$.

- Education/childcare staff reported higher mental well-being (median score 69.5, $\mathrm{p}=0.0082$ ) and higher physical wellbeing (median score $81, \mathrm{p}<0.0001$ ) than non-education/ childcare staff.

- Staff in sectors with few respondents $(\mathrm{n}=31)$, including key public services, essential goods production/sale and public safety, reported feeling more troubled by other people's actions (median score 71) compared with staff in NHS/ health, social care, government and education/childcare sectors $(p=0.0408)$.

\section{Qualitative themes}

Respondents described a variety of actions they felt were wrong and offered suggestions to prevent similar situations or reduce the impact. Some staff spoke of 'immense guilt', were highly critical of authority figures or gave detailed emotional stories whereas others simply offered brief suggestions.

Table 1 summarises staff comments and provides prompts for action (developed by AK) since system change can take time but everyone can be empowered to make a difference. Examples of individual quotes were shared locally as a powerful way of promoting change. ${ }^{8}$

Some themes appeared specific to particular staff groups. For example, concerns about patient/client care were particularly reported by health and care staff. Concerns included feeling that elderly people were being 'written off' and refused care or that 'vital info is being missed' by telephone consultation.

\section{DISCUSSION}

This survey met the aim of exploring essential workers' experience of moral injury, actions staff felt were wrong and what might help. Results suggest moral injury is a significant issue for many essential workers. This reflects research in other staff groups. ${ }^{9}$ It is interesting, however, that staff reported being more troubled by the actions of other people, than their own actions, since examples involving the latter may be easier to convey sympathetically than disgust or anger. ${ }^{10}$

Variation in moral injury across employment sectors could suggest areas for investigation or intervention, however, considerable distress was present in some respondents across all sectors. 
Table 1 Qualitative themes and prompts for action

\begin{tabular}{|c|c|c|c|}
\hline Prevention theme & Actions staff felt were wrong & Staff suggestions & Prompts for action \\
\hline Supervisor check-ins & $\begin{array}{l}\text { Strong emotions were noted regarding a perceived lack of } \\
\text { contact with managers/supervisors. This created a sense } \\
\text { of isolation, lack of value and lack of opportunity to raise } \\
\text { issues that could be dealt with. }\end{array}$ & $\begin{array}{l}\text { Regular supportive check ins with managers, informal } \\
\text { team meetings and accessible 'Mental Health Support' }\end{array}$ & $\begin{array}{l}\text { Who will you contact to let them know what you, or } \\
\text { your staff, need from them to function well? } \\
\text { How can you connect with staff to meet their needs } \\
\text { and concerns? }\end{array}$ \\
\hline Kindness & $\begin{array}{l}\text { Staff reported receiving 'Verbal abuse from colleagues } \\
\text { due to their own stress levels', being 'told off' for raising } \\
\text { 'serious safety concerns' and a 'public perception that } \\
\text { nurses are carrying disease'. Impacts of these issues } \\
\text { affected well-being and functioning. }\end{array}$ & $\begin{array}{l}\text { Educating the public, 'Challenging toxic behaviours } \\
\text { within teams' and support for senior staff 'to manage } \\
\text { their own emotions'. It was noted that a 'command } \\
\text { and control' approach 'needs to be balanced with } \\
\text { kindness and compassion' }\end{array}$ & $\begin{array}{l}\text { What one small thing can you do, for one other person } \\
\text { today, that might help them feel supported and } \\
\text { connected? } \\
\text { What would help you to stay in enough control of your } \\
\text { emotions not to pass your stress on? }\end{array}$ \\
\hline Fair rules and enforcement & $\begin{array}{l}\text { Many staff felt frustrated or angry about rules not being } \\
\text { obeyed by colleagues, people in authority and the public. } \\
\text { There were some strong differing views about when } \\
\text { people should work from home and what fair sharing of } \\
\text { workload means. }\end{array}$ & $\begin{array}{l}\text { Rules 'need to be really clear, reasonable' and } \\
\text { 'enforced' with 'spot checks of buildings'. } \\
\text { Choices, collaboration and ample notice about role } \\
\text { allocation. Respondents asked that policies 'apply to } \\
\text { all' but also that 'individual needs' are taken in to } \\
\text { account. }\end{array}$ & $\begin{array}{l}\text { Who do you need to have a conversation with to better } \\
\text { understand each other's needs and values? } \\
\text { How are you ensuring rules are followed fairly? } \\
\text {... and balancing that with individual need? }\end{array}$ \\
\hline $\begin{array}{l}\text { Effective communication and } \\
\text { processes (the way things are } \\
\text { done) }\end{array}$ & $\begin{array}{l}\text { A 'lack of communication' from government, } \\
\text { organisations, leaders and between agencies or team } \\
\text { members was a frequent concern. } \\
\text { Respondents also reported being worried about the way } \\
\text { things are done, patient care, staff safety and apparent } \\
\text { lack of action on issues raised. }\end{array}$ & $\begin{array}{l}\text { Clearer communication and opportunity to raise } \\
\text { concerns and find solutions. } \\
\text { Staff had some specific ideas for example, have a } \\
\text { 'designated social worker" for each care home, } \\
\text { use of 'NHS mail to exchange information quickly' } \\
\text { and provision of adequate requested resources, } \\
\text { for example, Personal Protective Equipment (PPE), } \\
\text { uniform, equipment. }\end{array}$ & $\begin{array}{l}\text { What can you do to share ideas/solutions/feedback } \\
\text { or decisions clearly at the right time with the right } \\
\text { people? }\end{array}$ \\
\hline
\end{tabular}

Some staff suggestions (ensuring supervisor check-ins, kindness, better communication and changes to processes) have been mentioned previously in moral injury literature ${ }^{1}$ or staff wellbeing guidance. ${ }^{11}$ Other suggestions, including focusing on fair rules/enforcement, may reflect the pandemic response. Not all staff commenting will be morally injured. Further qualitative analysis could compare experiences of respondents with greater or lesser reported moral injury.

However, it is important that moral injury does not become a 'diagnostic' label since it is not a mental illness. ${ }^{1}$ While individual approaches may be easier to implement, they should not be at the expense of team, organisation, societal and government policy interventions which tackle the underlying causes of moral injurious environments. ${ }^{5}$ Indeed, respondents to this survey suggested many practical actions that a variety of stakeholders could take.

A draft framework for action is under development locally ${ }^{8}$ but a wider strategy to address moral injury is critical for staff well-being, staff retention and vital service delivery. Further evidence regarding how to reduce morally injurious events and address moral injury post-event (particularly moral injury caused by others' actions) could make such a strategy more effective.

Limitations of this survey include limited geographical coverage, variation in response rates across employment sectors and use of simple self-rated sliders for moral injury. However, responses and the draft framework could suggest simple, good practice actions for system and organisational leaders to reduce and mitigate moral injury together in the same way we do for physical injuries.

Acknowledgements Thanks to members of the multiagency group who contributed to the design and dissemination of the survey, including Lyn Williams, Jo Murray, Andrew Moore, Jane Sunter, Clare Leeds and Lucy Treanor.

Contributors CG analysed survey results, produced an initial draft of the paper and revised it after other author comments. EK suggested changes and drafted sections of the introduction and discussion. AK drafted 'Prompts for action' in table 1. PP suggested changes, offered comment on drafts and assisted with analysis. All authors contributed to design and implementation of the survey.

Funding The authors have not declared a specific grant for this research from any funding agency in the public, commercial or not-for-profit sectors.

Competing interests None declared.

Patient consent for publication Not applicable.
Ethics approval This study confirmed with North East-Tyne and Wear South Ethics Committee (Health Research Authority) that the study does not require ethical oversight (ethical oversight waived). This study was part of a Service Evaluation exempted this study.

Provenance and peer review Not commissioned; externally peer reviewed.

Supplemental material This content has been supplied by the author(s). It has not been vetted by BMJ Publishing Group Limited (BMJ) and may not have been peer-reviewed. Any opinions or recommendations discussed are solely those of the author(s) and are not endorsed by BMJ. BMJ disclaims all liability and responsibility arising from any reliance placed on the content. Where the content includes any translated material, BMJ does not warrant the accuracy and reliability of the translations (including but not limited to local regulations, clinical guidelines, terminology, drug names and drug dosages), and is not responsible for any error and/or omissions arising from translation and adaptation or otherwise.

\section{ORCID iD}

Catherine Guy http://orcid.org/0000-0002-9148-3444

\section{REFERENCES}

1 Greenberg N, Docherty M, Gnanapragasam S, et al. Managing mental health challenges faced by healthcare workers during covid-19 pandemic. BMJ 2020;368:m1211.

2 Kopacz MS, Ames D, Koenig HG. It's time to talk about physician burnout and moral injury. Lancet Psychiatry 2019;6:e28.

3 Mantri S, Lawson JM, Wang Z, et al. Prevalence and predictors of moral injury symptoms in health care professionals. J Nerv Ment Dis 2021;209:174-80.

4 Chen Q, Liang M, Li Y, et al. Mental health care for medical staff in China during the COVID-19 outbreak. Lancet Psychiatry 2020;7:e15-16.

5 Goddard AF, Patel M. The changing face of medical professionalism and the impact of COVID-19. Lancet 2021;397:950-2.

6 Cabinet office and Department of Education. Guidance: Children of critical workers and vulnerable children who can access schools or educational settings. Gov.uk. [Online], 2021. Available: https://www.gov.uk/government/publications/coronaviruscovid-19-maintaining-educational-provision/guidance-for-schools-colleges-and-localauthorities-on-maintaining-educational-provision

7 Steering group. How has Covid-19 affected you? survey monkey, 2021. Available: https://www.surveymonkey.co.uk/r/3XK8R63

8 Recovery College Online. Moral injury and staff wellbeing. recovery College online, 2021. Available: https://www.recoverycollegeonline.co.uk/your-mental-health/ coronavirus/for-staff/moral-injury-and-staff-wellbeing/

9 Williamson V, Stevelink SAM, Greenberg N. Occupational moral injury and mental health: systematic review and meta-analysis. Br J Psychiatry 2018;212:339-46.

10 BBC News. Coronavirus: Why healthcare workers are at risk of moral injury. BBC News. [Online], 2020. Available: https://www.bbc.co.uk/news/world-us-canada52144859

11 Williams R. The top ten messages for supporting healthcare staff during the COVID-19 pandemic. Royal College of psychiatrists, 2021. Available: https://www.rcpsych.ac.uk/ docs/default-source/about-us/covid-19/top-ten-messages-williams-et-al.pdf?sfvrsn= 990e3861_0 